\title{
Chromoendoscopy with hematoxylin in the classificaton of gastric lesions
}

\author{
Serguei Mouzyka and Alexandra Fedoseeva \\ Hospital “LISSOD”, Malyshko Street 27, Plyuty, Kiev 08720, Ukraine
}

\begin{abstract}
Background. Hematoxylin is a basic histological stain which stains nuclei. Apparently, it can be used with endoscopy to diagnose malignant lesions due to their increased nucleus-tocytoplasm ratio. The aim of this study was to evaluate the use of hematoxylin in the differentiation of gastric lesions. Methods. Part 1. In a prospective study, a total of 70 different gastric abnormalities were stained with $1 \%$ hematoxylin solution during upper endoscopy. Results of histological examinations were compared with endoscopic findings. Part 2. During a 5-day period, antral mucosa was stained with hematoxylin in all patients $(n=26)$, independent of the upper endoscopy results. Grades of stained mucosa were compared with the proliferating cell nuclear antigen (PCNA) index, which was examined using an immunohistochemical method. Part 3. Gastric biopsies (total, 12) were obtained from the stained and unstained areas within the limits of one lesion (total, 6) after chromoscopy with hematoxylin and examined with monoclonal (PCNA) antibodies.

Results. Using histological findings, the sensitivity and specificity of chromoendoscopy with hematoxylin for detecting gastric neoplasia and adenocarcinoma were determined. A significant positive correlation $(r=0.81 ; P<0.001)$ was found between the PCNA index and grade of endoscopic stained mucosa. The PCNA index was increased in stained areas of gastric abnormalities in comparison to unstained areas within the limits of one lesion in all six patients.

Conclusion. Chromoendoscopy with hematoxylin increases opportunities for precision biopsy. The grade of endoscopic stained mucosa depends on epithelial cell proliferation and is associated with malignancy. By using histology as the main outcome, the sensitivity and specificity of chromoendoscopy
\end{abstract}

Offprint requests to: S. Mouzyka

Part of this study was presented at the 12th United European Gastroenterology Week (UEGW), Prague 2004; citation: Endoscopy 2004; 36 (Suppl I) A246, and the 13th United European Gastroenterology Week (UEGW), Copenhagen 2005; citation: Gut 2005; 54 (Suppl VII) A119.

Received: August 14, 2007 / Accepted: November 19, 2007 with hematoxylin for diffuse staining in the detection of gastric neoplasia and adenocarcinoma were $92.9 \%$ and $89.3 \%$, respectively.

Key words Endoscopy $\cdot$ Chromoendoscopy $\cdot$ Hematoxylin

\section{Introduction}

The early detection of neoplasias (the precursors of cancer) in asymptomatic persons offers a much better outlook if detection and treatment occur at an early stage. Often, early detection is triggered by screening the application of a diagnostic procedure of a person with neither signs nor symptoms of disease [1]. Chromoendoscopy or tissue staining is an "old" endoscopic technique that has been used for decades [2]. "Chromoscopy" is a recently coined term, which denotes the use of colored materials to enhance the accuracy of endoscopic examination. In gastrointestinal endoscopy, dyes or stains have primarily been utilized to enhance the detection of diseased areas, to guide endoscopic biopsies, and to obtain better visual diagnosis or characterization of small abnormalities [3]. Hematoxylin is a basic histological stain which stains nuclei. The most useful cationic dye is derived from hematoxylin, a dye extracted from the heartwood of a Central American tree. Hematein is produced by oxidation, and this, when mordanted with $\mathrm{Al}, \mathrm{Cr}$, or Fe forms a useful dye, commonly referred to as "hematoxylin" [4]. Despite the existence of many described dyes, there is no work studying the effectiveness of chromoendoscopy with hematoxylin.

Apparently, hematoxylin can be used with endoscopy to diagnose malignant lesions because of their increased nucleus-to-cytoplasm ratio. The aim of this study was to evaluate the use of hematoxylin in the differentiation of gastric lesions. 


\section{Patients, materials, and methods}

All endoscopic examinations were performed after obtaining permissions from patients. The first lesion stained by hematoxylin was histologically described gastric adenocarcinoma. We used hematoxylin with brown tint (Mayer). Then we observed adequate staining, but there was an absence of contrast between the mucosa and the stain. Hence, subsequently, we used deep-purple hematoxylin (Weigert) only [5].

All endoscopic procedures were performed by a single endoscopist with a fiberendoscope (GIFQ30; Olympus, Tokyo, Japan) connected with a camera and videoendoscope (EVE-W88A; Fujinon, Tokyo, Japan). A catheter (Olympus) was used to spray reagents onto the gastric mucosa, in the following order: $5 \%$ sodium carbonate solution, $1 \%$ hematoxylin solution, and after $1 \mathrm{~min}$, intensive water irrigation.

The volume of each reagent depended on the size of the abnormalities (from 2 to $4 \mathrm{ml}$ of hematoxylin solution). All examinations were videotaped and photographed. The overall hematoxylin staining pattern on the mucosa was classified into three groups: group A, no appreciable staining; group B, patchy (Fig. 1); and group C, diffuse (Fig. 2).

\section{Part 1}

A total of 69 patients with 70 various gastric abnormalities participated in a prospective study between April 2004 and January 2005 (Table 1).

Gastric lesions were localized in the antrum (58), body (8), and cardia (4). Exclusion criteria for our study were earlier diagnosed adenocarcinoma and refusal of a patient. Biopsy specimens were obtained from hematoxylin-stained areas as well as hematoxylin-unstained areas. From 6 to 8 specimens were taken from each lesion with standard biopsy forceps (FB-24E-1; Olympus). Formalin-fixed samples were stained with H\&E. Using the Vienna classification of gastrointestinal epithelial neoplasia [6], the results of histological examinations were compared with endoscopic findings.

\section{Part 2}

In a prospective 5-day study, antral mucosa was stained with $1 \%$ hematoxylin solution in all patients, independent of upper endoscopy results (total, 26 adults). All endoscopic procedures were performed by a single endoscopist. Biopsy specimens were obtained from all patients, from stained mucosa as well as unstained antral mucosa. Specimens were fixed in $10 \%$ buffered formaldehyde solution, embedded in paraffin, and stained immunohistochemically with monoclonal proliferating cell nuclear antigen (PCNA) antibodies.

Immunohistochemical (IHC) staining was performed using the standard avidin-biotin peroxidase complex

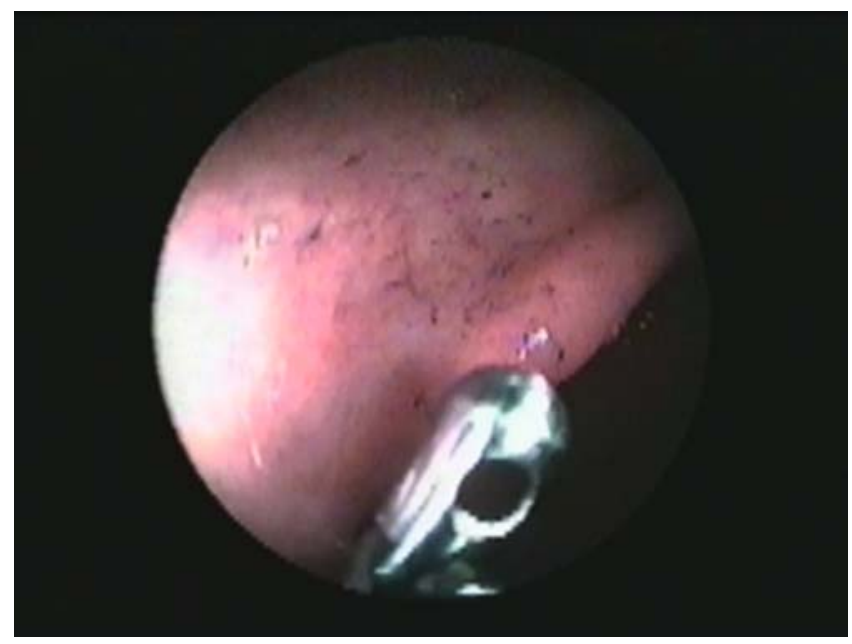

Fig. 1. Endoscopic image of patchy staining of antral mucosa, which is maintained after intensive water irrigation

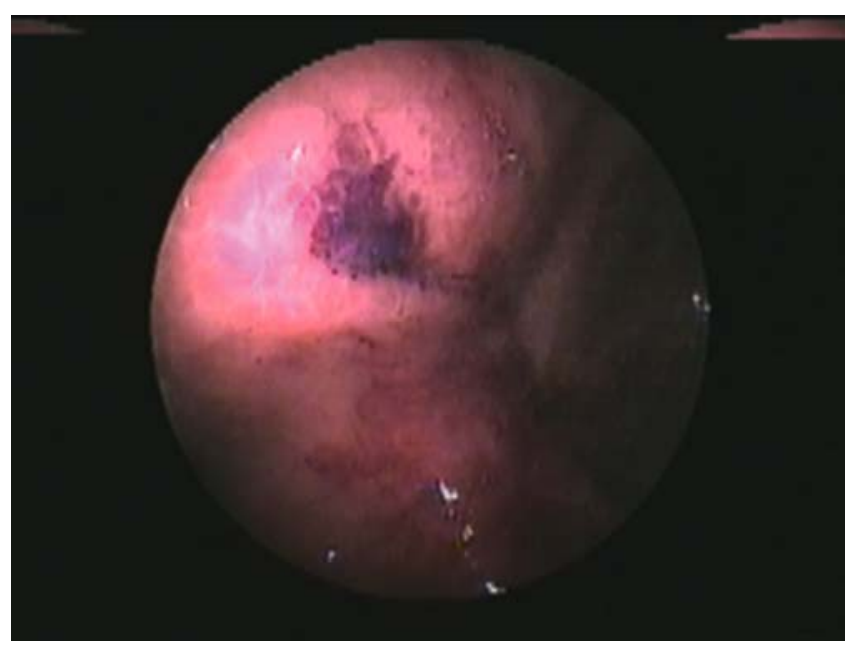

Fig. 2. Endoscopic image of diffuse hematoxylin staining of antral mucosa. Histological examination showed low-grade cancer

Table 1. Gastric lesions included in the study

\begin{tabular}{lcccccc}
\hline Nodules & Polyps & Friable mucosa & Erosions & Ulcers & Scars & Total \\
\hline 24 & 6 & 6 & 17 & 11 & 6 & 70 \\
\hline
\end{tabular}


$(\mathrm{ABC})$ method with a Vectastain ABC Elite kit (Vector, Burlingame, CA, USA). Serial sections were deparaffinized, and after endogenous peroxidase activity was blocked with $3 \%$ hydrogen peroxide in distilled water for $5 \mathrm{~min}$, the sections were microwaved in citrate buffer (pH 6.1) for $30 \mathrm{~min}$ for antigen retrieval. Nonspecific binding was blocked with 5\% normal horse serum in phosphate-buffered saline (PBS) at room temperature for $30 \mathrm{~min}$. Incubation was performed with anti-mouse human PCNA (clone PC 10) monoclonal antibody (Dako, Copenhagen, Denmark) at 1:200 dilution. Sections of tissue known to be positive were used as controls. For negative controls, exposure to the primary antibody was omitted. Color was developed using 3, 3'diaminobenzidine, and microscopic evaluation was performed in a blind fashion without knowledge of the patient group.

Quantitative estimation of IHC was performed according to a system for the evaluation and grading of immunostaining patterns with multiple values for extent and intensity, giving index values of 0 to 9 [7]. The extent of staining was scored on a semiquantitative scale of 0 to 3 , using the following criteria: 0 , no detectable staining; 1 , less than $10 \%$ scattered cells; 2 , more than $10 \%$ but less than $50 \%$ stained cells; 3 , homogeneous staining in more than $50 \%$ of cells. The intensity of staining was similarly scored: 0 , no detectable staining; 1 , weakly stained nuclei; 2 , moderately stained nuclei; 3 , strongly stained nuclei. Final indexes were derived from the multiplication of extent by intensity.

Grades of hematoxylin-stained mucosa were compared with epithelial cell proliferation, which was examined in superficial gastric epithelium (Fig. 3).

\section{Part 3}

Gastric biopsies (total, 12) were obtained from six patients in the prospective study. The patients had different abnormalities (ulcers, erosions, nodules) diagnosed during upper gastrointestinal endoscopy. Specimens for pathological examinations were obtained from the hematoxylin-stained area and the hematoxylin-unstained area within the limits of one lesion. The origin of the specimens was unknown to the pathologist. In all cases, IHC staining with monoclonal PCNA antibodies was done by using the described methodology. The PCNA index was compared in stained and unstained areas within the limits of one lesion.

\section{Results}

\section{Part 1}

Between May 2004 and May 2005, 69 patients with 70 different gastric abnormalities were studied. Of the 69 patients, 28 (40.6\%) were women and 41 (59.4\%) were men; the patients' mean age was 53 years (range, 23-92 years). It was estimated that the technique added between 3 and $5 \mathrm{~min}$ to the length of the examination. Six patients complained about a change of stool color (greenish hue) during the next day. There were no other side effects or complications after chromoendoscopy. Histological findings are shown in Table 2.

Using histology as the main outcome (Fig. 4), the sensitivity and specificity of chromoendoscopy with hematoxylin for diffuse staining in the detection of gastric neoplasia and adenocarcinoma were $92.9 \%$ [ $95 \%$ confidence intervals (CI), $79.5 \%$ to $106.3 \%$ ] and $89.3 \%$ (95\% CI, $28.7 \%$ to $149.9 \%$ ), respectively. The positive predictive value was $68.4 \%$ (95\% CI, $47.5 \%$ to $89.3 \%$ ), and the negative predictive value was $98 \%$ (95\%, CI $94.2 \%$ to $101.8 \%$ ) and the likelihood ratio for a positive result was 8.68. A significant positive correlation (Pearson coefficient $0.64 ; P<$ 0.001 ) was found between grade of endoscopic hematoxylin-stained mucosa and gastric neoplasia and adenocarcinoma.

Table 2. Results of histological examinations compared with grade of endoscopic stained mucosa

\begin{tabular}{|c|c|c|c|c|}
\hline & Group A & Group B & Group C & Total \\
\hline Inflammatory changes & 6 & 5 & 1 & 12 \\
\hline Foveolar hyperplasia & 2 & 10 & & 12 \\
\hline Ulcer & & 2 & 2 & 4 \\
\hline Erosion & 1 & 12 & 1 & 14 \\
\hline Scar & & 4 & 1 & 5 \\
\hline Adenoma & & 8 & 1 & 9 \\
\hline Low-grade intraepithelial neoplasia & & 1 & 8 & 9 \\
\hline High-grade intraepithelial neoplasia & & & 2 & 2 \\
\hline Low-grade cancer & & & 1 & 1 \\
\hline Intermediate cancer & & & 1 & 1 \\
\hline High-grade cancer & & & 1 & 1 \\
\hline Total & 9 & 42 & 19 & 70 \\
\hline
\end{tabular}




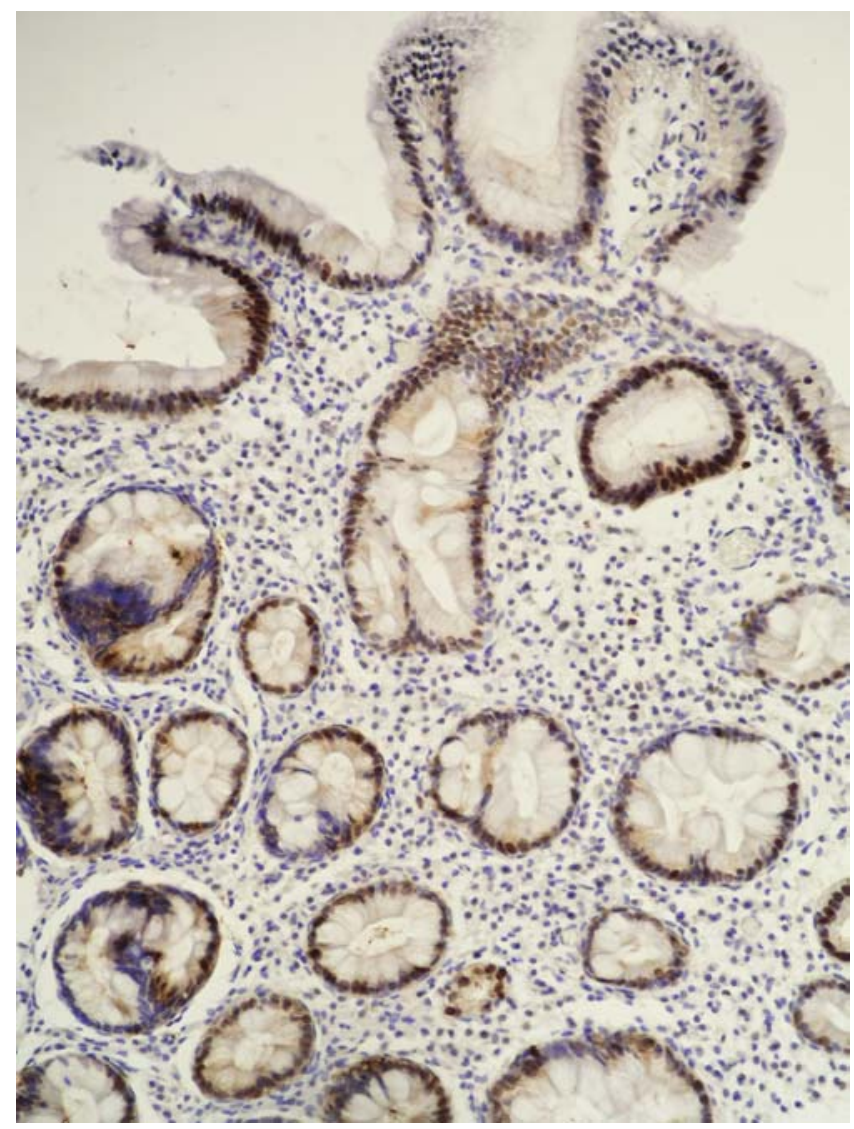

Fig. 3. Histological features of tissue with high proliferating cell nuclear antigen (PCNA) index. There are more than $50 \%$ scattered cells, and strongly stained nuclei are present in superficial gastric epithelium. $\times 100$
Part 2

In the 26 patients, the endoscopic hematoxylin-staining pattern on the mucosa was classified into: group A (3), group B (17), and group C (6). The PCNA index was lowest in the unstained mucosa and highest in the diffusely stained mucosa (Table 3 ).

A significant positive correlation (Pearson coefficient $0.81 ; P<0.001)$ was found between the PCNA index and the grade of endoscopic hematoxylin-staining. The Pearson coefficient between the intensity and extent of the PCNA index and the grade of staining was 0.77 and 0.73 , respectively $(P<0.001$ and $P<0.001)$.

In our patients we did not observe a correlation between the PCNA index and age $(r=-0.028 ; P>0.05)$, or between the PCNA index and sex $(r=-0.21$; $P>0.05)$.

\section{Part 3}

The PCNA index was found to be increased in the hematoxylin-stained areas of gastric abnormalities in comparison to the hematoxylin-unstained areas within the limits of one lesion in all six patients (Table 4).

\section{Discussion}

Compared to other evolving diagnostic modalities such as fluorescence spectroscopy, fluorescence endoscopy, and optical coherence tomography, chromoendoscopy

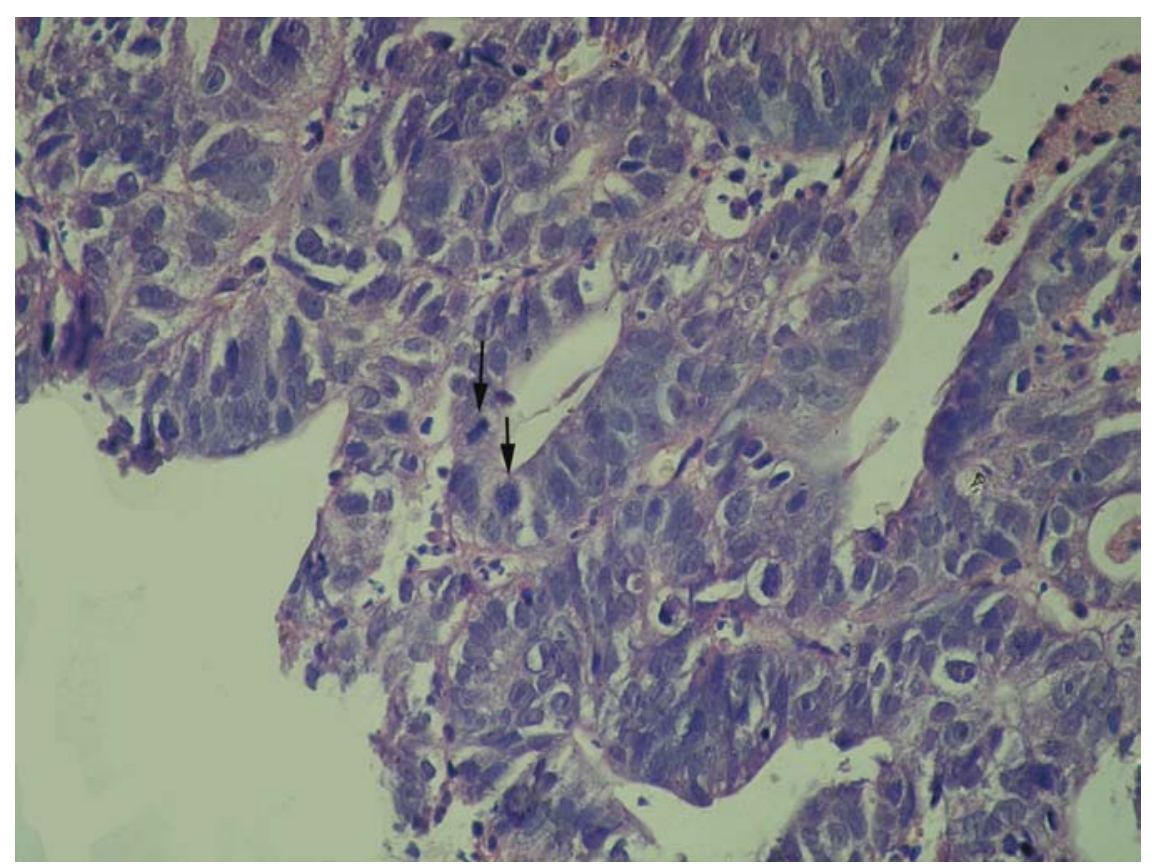

Fig. 4. Histological examination showed low-grade cancer. Hematoxylin and eosin, $\times 400$ 
Table 3. PCNA expression compared with grade of endoscopic stained mucosa

\begin{tabular}{|c|c|c|c|c|c|c|c|}
\hline Patient & $\begin{array}{c}\text { Age } \\
\text { (years) }\end{array}$ & Sex & Gastric lesion & $\begin{array}{l}\text { Grade of stained } \\
\text { mucosa }\end{array}$ & PCNA: intensity & PCNA: extent & PCNA: index \\
\hline 1 & 66 & M & Nodule & $\mathrm{B}$ & 2 & 3 & 6 \\
\hline 2 & 39 & $\mathrm{~F}$ & Normal & A & 1 & 1 & 1 \\
\hline 3 & 52 & $\mathrm{~F}$ & Erosion & $\mathrm{B}$ & 1 & 1 & 1 \\
\hline 4 & 42 & $\mathrm{M}$ & Nodule & B & 2 & 1 & 2 \\
\hline 5 & 61 & $\mathrm{M}$ & Erosion & $\mathrm{B}$ & 1 & 1 & 1 \\
\hline 6 & 32 & $\mathrm{M}$ & Erosion & $\mathrm{B}$ & 1 & 2 & 2 \\
\hline 7 & 27 & M & Nodule & $\mathrm{C}$ & 3 & 3 & 9 \\
\hline 8 & 53 & M & Friable & B & 2 & 2 & 4 \\
\hline 9 & 40 & M & Normal & B & 1 & 1 & 1 \\
\hline 10 & 65 & $\mathrm{~F}$ & Nodule & $\mathrm{B}$ & 2 & 1 & 2 \\
\hline 11 & 45 & $\mathrm{~F}$ & Scar & B & 1 & 1 & 1 \\
\hline 12 & 28 & $\mathrm{~F}$ & Erosion & B & 1 & 1 & 1 \\
\hline 13 & 24 & $\mathrm{M}$ & Normal & A & 1 & 1 & 1 \\
\hline 14 & 24 & $\mathrm{M}$ & Erosion & $\mathrm{B}$ & 2 & 1 & 2 \\
\hline 15 & 48 & $\mathrm{M}$ & Normal & A & 1 & 1 & 1 \\
\hline 16 & 30 & $\mathrm{M}$ & Erosion & $\mathrm{B}$ & 1 & 2 & 2 \\
\hline 17 & 52 & M & Nodule & B & 1 & 1 & 1 \\
\hline 18 & 38 & M & Ulcer & $\mathrm{C}$ & 3 & 3 & 9 \\
\hline 19 & 44 & $\mathrm{~F}$ & Nodule & B & 2 & 1 & 1 \\
\hline 20 & 31 & M & Erosion & $\mathrm{C}$ & 3 & 3 & 9 \\
\hline 21 & 67 & $\mathrm{M}$ & Erosion & B & 1 & 1 & 1 \\
\hline 22 & 63 & $\mathrm{M}$ & Nodule & B & 2 & 1 & 2 \\
\hline 23 & 55 & $\mathrm{~F}$ & Erosion & $\mathrm{C}$ & 3 & 3 & 9 \\
\hline 24 & 67 & $\mathrm{M}$ & Scar & $\mathrm{C}$ & 3 & 2 & 6 \\
\hline 25 & 57 & $\mathrm{~F}$ & Nodule & B & 2 & 1 & 2 \\
\hline 26 & 52 & $\mathrm{M}$ & Ulcer & $\mathrm{C}$ & 2 & 3 & 6 \\
\hline
\end{tabular}

Table 4. Comparison of PCNA indexes in stained and unstained areas within the limits of one lesion

\begin{tabular}{|c|c|c|c|c|c|c|}
\hline & \multicolumn{2}{|c|}{ PCNA: intensity } & \multicolumn{2}{|c|}{ PCNA: extent } & \multicolumn{2}{|c|}{ PCNA: index } \\
\hline & Stained & Unstained & Stained & Unstained & Stained & Unstained \\
\hline 1 & 2 & 1 & 1 & 1 & 2 & 1 \\
\hline 2 & 3 & 3 & 3 & 2 & 9 & 6 \\
\hline 3 & 3 & 2 & 3 & 3 & 9 & 6 \\
\hline 4 & 3 & 1 & 2 & 1 & 6 & 1 \\
\hline 5 & 2 & 1 & 1 & 1 & 2 & 1 \\
\hline 6 & 2 & 2 & 3 & 2 & 6 & 4 \\
\hline
\end{tabular}

is an effective technique already available to the endoscopist to improve visualization and diagnosis. It is simple, quick, widely available, inexpensive, and free of adverse effects. It is useful in both clinical practice and endoscopic research [8]. Recent video endoscope models with high resolution are suitable for the early detection of the nonprotruding precursors of advanced cancer. However, the proportion of false-negative procedures is far from zero. Nonprotruding depressed 0-IIc neoplastic lesions are invariably neglected if endoscopists do not bear in mind the discolored spots that correspond to these lesions and if chromoendoscopy is not routinely used [9]. False-negative findings in gastroscopy for early gastric cancer have recently been estimated at $19 \%$ in Japan [10]. Moreover, high-resolution endoscopy with known stains is not an inexpensive method and demands additional time for examination of the stained mucosal surface. Previously, there was no simple method for the detection of gastric neoplasia (such as Lugol solution for esophageal mucosa). Our experience of chromoendoscopy with hematoxylin shows very easy interpretation of the pattern. This method may be used with all models of endoscopes with equivalent effective results. It confirms a high level of sensitivity and specificity of diffuse staining for detecting gastric neoplasia and adenocarcinoma. In our work we did not aim to study the effectiveness of conventional endoscopic observation in the detection of gastric neoplasia. We examined the correlation between the results of chromoendoscopy with hematoxylin and pathology reports. 
For examination of the connection between chromoendoscopy with hematoxylin and cancerogenesis, we used an immunohistochemical (IHC) method with PCNA antigens. PCNA was originally identified by immunofluorescence as a nuclear protein whose appearance correlated with the proliferative state of the cell. A cell cycle-dependent protein described by Bravo (called cyclin) was shown to be identical to PCNA. The PCNA protein has been highly conserved during evolution; the deduced amino acid sequences of rat and human PCNA differ by only 4 of 261 amino acids [11]. Travali et al. [12] have shown that the human PCNA gene is present in a single copy and has six exons.

PCNA is required for the replication of SV40 DNA in vitro and has been identified as the auxiliary protein (cofactor) for DNA polymerase delta. Unlike DNA polymerases alpha, beta, and gamma, DNA polymerase delta has exonuclease activity. Because the exonuclease activity is in the 3-primeto-5-prime direction, DNA polymerase delta has proofreading activity and is expected to play a significant role in the maintenance of the fidelity of mammalian DNA replication [11]. Proliferating cell nuclear antigen (PCNA) is an essential protein for both DNA replication and DNA repair [13]. DNA polymerase delta proofreading suppresses spontaneous tumor development and strongly suggests that unrepaired DNA polymerase errors contribute to cancerogenesis [14]. However, some publications have noted PCNA positivity in necroinflammatory disorders, something which is difficult to explain solely on the basis of cell proliferation $[15,16]$.

Many research examples have shown significantly higher PCNA indexes in gastrointestinal tumors than in benign diseases [17-19]. This observation is also true for gastric adenocarcinoma [20-22]. Moreover, the PCNA index is an important prognostic marker for advanced gastric cancers [23], for the metastatic potential of gastric cancers [24], for survival [25], and for a high grade of tumor malignancy [26]. Matturri et al. [25] and Wu et al. [27] concluded that PCNA index may be useful in predicting the aggressiveness of a tumor and in identifying patients in need of additional perioperative therapies. In an examination of 71 surgically removed specimens from patients with gastric cancer, abnormal expressions of PCNA were associated with malignant potential, lymph node metastasis, and clinical stage [28]. However, in all known research, authors have used only the parameter of extent for the estimation of PCNA expression. In our study, the parameters of extent and intensity were used. This makes the PCNA index (of 0 to 9) more informative. In 841 patients who had undergone gastrectomy for gastric cancer at Seoul National University Hospital, a PCNA index of 50 or more was positively correlated with older age, male sex, larger tumor size, and well-differentiated histology [22].
In our patients we did not observe a correlation of the PCNA index with age or sex. Data on the influence of Helicobacter pylori infection on the PCNA index are inconsistent. One author shows that in the case of an infection, a high PCNA index is observed $[29,30]$, while others do not find such dependence [31]. In our work we did not aim to study the influence of $H$. pylori infection on the PCNA index. We examined the correlation between the results of chromoendoscopy and the PCNA index only.

We found differences between the PCNA indexes in the stained and unstained areas within the limits of one lesion in all cases, which can testify to a positive role of chromoendoscopy with hematoxylin in precision biopsy.

Although there was a good correlation between staining and neoplasia when specific lesions were examined in our first part of experiments, there were a number of false-positives in the second part of experiments where there was unselected mucosa and especially so where the unselected mucosa contained a nodular lesion and an erosion. These discrepancies suggest that more extensive prospective analysis of this technique would be desirable.

\section{Conclusion}

The grade of hematoxylin-stained mucosa depends upon epithelial cell proliferation and is associated with malignancy. Chromoendoscopy with hematoxylin increases the opportunity for precision biopsy of gastric abnormalities.

\section{References}

1. Lambert R. What is the role of individual screening in the prevention of digestive cancer? Gastrointest Endosc 2003;53:401-3.

2. Fennerty MB. Tissue staining. Gastrointest Endosc Clin N Am 1994:4:297-311.

3. Shim CS. Staining in gastrointestinal endoscopy: clinical application and limitations. Endoscopy 1999;31:487-96.

4. Walter JB, Talbot IC. General pathology. New York: Churchill Livingstone; 1996.

5. Lillie RD. Histopathologic technique and practical histochemistry. New York: McGraw-Hill; 1965.

6. Schlemper RJ, Riddell RH, Kato Y, Borchard F, Cooper HS, Dawsey SM, et al. The Vienna classification of gastrointestinal epithelial neoplasia. Gut 2000;47:251-5.

7. Trosko JE. Role of low-level ionizing radiation in multi-step carcinogenic process. Health Phys 1996;70:812-22.

8. Canto MI. Staining in gastrointestinal endoscopy: the basics. Endoscopy 1999;31:479-86.

9. Endoscopic Classification Review Group. Update on the Paris classification of superficial neoplastic lesions in the digestive tract. Endoscopy 2005;37:570-8.

10. Hosokawa O, Tsuda S, Kidani E, Watanabe K, Tanigawa Y, Shirasaki S, et al. Diagnosis of gastric cancer up to 3 years after 
negative upper gastrointestinal endoscopy. Endoscopy 1998;30: 669-74.

11. Suzuka I, Daidoji H, Matsuoka M, Kadowaki K, Takasaki Y, Nakane PK, et al. Gene for proliferating-cell nuclear antigen (DNA polymerase delta auxiliary protein) is present in both mammalian and higher plant genomes. Proc Natl Acad Sci USA 1989;86:3189-93.

12. Travali S, Ku D-H, Rizzo MG, Ottavio L, Baserga R, Calabretta B. Structure of the human gene for the proliferating cell nuclear antigen. J Biol Chem 1989;264:7466-72.

13. Yamamoto T, Mori Y, Ishibashi T, Uchiyama Y, Ueda T, Ando $\mathrm{T}$, et al. Interaction between proliferating cell nuclear antigen (PCNA) and a DnaJ induced by DNA damage. J Plant Res 2005; 118:91-7.

14. Goldsby RE, Hays LE, Chen X, Olmsted EA, Slayton WB, Spangrude GJ, et al. High incidence of epithelial cancers in mice deficient for DNA polymerase delta proofreading. Proc Natl Acad Sci USA 2002;99:15560-5.

15. Wolf HK, Michalopoulos GK. Hepatocyte regeneration in acute fulminant and non-fulminant hepatitis: a study of proliferating cell nuclear antigen expression. Hepatology 1992;49:707-13.

16. Kawakita N, Seki S, Sakaguchi H, Yanai A, Kuroki T, Mizoguchi $\mathrm{Y}$, et al. Analysis of proliferating hepatocytes using a monoclonal antibody against proliferating cell nuclear antigen/cyclin in embedded tissues from various liver diseases fixed in formaldehyde. Am J Pathol 1992;140:513-20.

17. Kullmann F, Fadaie M, Gross V, Knuchel R, Bocker T, Steinbach $\mathrm{P}$, et al. Expression of proliferating cell nuclear antigen (PCNA) and Ki-67 in dysplasia in inflammatory bowel disease. Eur J Gastroenterol Hepatol 1996;8:371-9.

18. Can B, Sökmensüer C. Clinicopathologic features, cellular differentiation, PCNA and P53 expressions in gastrointestinal stromal tumors. Hepatogastroenterology 2003;50(Suppl 2):ccxliiiviii.

19. Belessi CJ, Parasi AS, Manioudaki HS, Laoutaris NP, Legakis NC, Peros GT, et al. Prognostic impact of DNA ploidy pattern, S-phase fraction (SPF), and proliferating cell nuclear antigen (PCNA) in patients with primary gastric lymphoma. J Surg Oncol 2003;82:247-55.

20. Ozercan IH, Bahcecioglu IH, Ozercan MR, Bozlak N, Dogan C, Yekeler H. Proliferating cell nuclear antigen and nucleolar organizer region for differential diagnosis of dysplasia and adenocarcinoma in gastric biopsies. Indian J Gastroenterol 2000;19:57-60.

\section{Editorial comment}

\section{Some precautions on the use of chromoendoscopy with hematoxylin in the classification of gastric lesions}

\author{
Noriya Uedo \\ Department of Gastrointestinal Oncology, Osaka Medical Center \\ for Cancer and Cardiovascular Diseases, 1-3-3 Nakamichi, \\ Higashinari-ku, Osaka 537-8511, Japan
}

In the study by Mouzyka and Fedoseeva [1], the authors used hematoxylin for chromoendoscopy in the stomach and indicated that it would be useful for detection of gastric neoplasia according to nuclear uptake of the dye by proliferating cells. The observations made in the study are quite interesting; however, we should understand the properties of the agent and clarify some issues before we widely apply the method to clinical practice.
21. Tseng HH, Hsu PI, Chen HC, Lai KH, Lo GH, Lo CC, et al. Compartment theory in Helicobacter pylori-associated gastric carcinogenesis. Anticancer Res 2003;23:3223-9.

22. Lee KE, Lee HJ, Kim YH, Yu HJ, Yang HK, Kim WH, et al. Prognostic significance of p53, nm23, PCNA and c-erbB-2 in gastric cancer. Jpn J Clin Oncol 2003;33:173-9.

23. Hirose K, Iida A, Yamaguchi A, Onchi H, Awata H, Katayama $\mathrm{K}$, et al. Prognostic value of DNA ploidy and proliferating cell nuclear antigen in gastric cancer. Oncology 1998;55: 300-6.

24. Terada R, Yasutake T, Nakamura S, Hisamatsu T, Nakagoe T, Ayabe $\mathrm{H}$, et al. Evaluation of metastatic potential of gastric tumors by staining for proliferating cell nuclear antigen and chromosome 17 numerical aberrations. Ann Surg Oncol 2001;8: $525-32$.

25. Matturri L, Biondo B, Cazzullo A, Colombo B, Giordano F, Guarino M, et al. Prognostic significance of different biological markers (DNA index, PCNA index, apoptosis, p53, karyotype) in 126 adenocarcinoma gastric biopsies. Anticancer Res 1998;18: 2819-25.

26. Czyzewska J, Guzinska-Ustymowicz K, Lebelt A, Zalewski B, Kemona A. Evaluation of proliferating markers Ki-67, PCNA in gastric cancers. Rocz Akad Med Bialymst 2004;49(Suppl 1): 64-6.

27. Wu K, Zhao L, Li Y, Shan YJ, Wu LJ. Effects of vitamin E succinate on the expression of Fas and PCNA proteins in human gastric carcinoma cells and its clinical significance. World $\mathrm{J}$ Gastroenterol 2004;10:945-9.

28. Ji SQ, Hua YW, Zhuang J, Gao Y, Kong Y, Han SL, et al. Significance of COX-2, p53, proliferating cell nuclear antigen and $\mathrm{nm} 23$ expressions in gastric cancer and its behavior (in Chinese). Ai Zheng 2002;21:619-24.

29. Rokkas T, Liatsos C, Karameris A, Petridou E, Lazaris A, Antoniades D, et al. Proliferating cell nuclear antigen (PCNA) immunostaining in Helicobacter pylori infection: impact of eradication. Pathol Oncol Res 1999;5:304-8.

30. Nagata J, Kijima H, Takagi A, Ito M, Goto K, Yamazaki H, et al. Helicobacter pylori induces chronic active gastritis in p53-knockout mice. Int J Mol Med 2004;13:773-7.

31. Unger Z, Molnar B, Szaleczky E, Torgyekes E, Muller F, Zagoni $\mathrm{T}$, et al. Effect of Helicobacter pylori infection and eradication on gastric epithelial cell proliferation and apoptosis. J Physiol Paris 2001;95:355-60.

Hematoxylin is a natural extract from the heartwood of the tree Haematoxylum campechianum. Despite common use of hematoxylin in histological routine, it is not itself the dye. It is usually converted into hematein with a chemical oxidizing agent and is used together with a mordant, the two most common being aluminum or iron. The cationic complex of hematein and the mordant binds to anionic nuclear chromatin as the most frequently stained tissue component. An aluminum mordant is used in the hematoxylin and eosin general method (Meyer's method), and ferric salts are used for acid-resistant nuclear staining. The latter, Weigert's iron hematoxylin solution [2], which usually includes hematoxylin, hydrochloride, ferric chloride, and alcohols, was used for chromoendoscopic vital staining in the study by Mouzyka and Fedoseeva. 
Information on the effects on human health from exposure to hematoxylin is limited, and quantitative toxicology has not been thoroughly investigated, probably because applying it in vivo has not been considered. It may cause irritation to the eye, skin, and respiratory tract, and large oral doses irritate the gastrointestinal tract. Generally, hazardous effects of hematoxylin itself are unlikely when it is used at low concentration and is handled appropriately, although they cannot be completely excluded. The International Agency for Research on Cancer and the National Toxicology Program list the substance as neither a toxic agent nor a carcinogen. Because it is used for staining as a mixture, the hazardous effects of other ingredients such as metallic salts or the organic solvent should also be considered, depending on composition and quantity. The lethal dose of Weigert's solution is not available in most material safety data sheets, but some report its oral LD50 as $900 \mathrm{mg} / \mathrm{kg}$ or $>10 \mathrm{~g} / \mathrm{kg}$ [3].

To date, several dyes, e.g., indigo carmine, methylene blue, Congo red, and others, have been applied in the stomach to detect and delineate gastric intestinal metaplasia, dysplasia, and early cancer. Chromoendoscopy is perceived to be a safe procedure, with the stains considered to be nontoxic at the concentrations used. Recently, methylene blue has been shown to induce oxidative DNA damage when exposed to white light in Barrett's esophagus [4], although there have been no reports of clinically relevant toxicity or enhanced cancer risk associated with this agent. No significant local or systemic toxicity has been reported with the topical use of other staining agents; however, none of them has been specifically cleared by the Food and Drug Administration for performance of chromoendoscopy [5].

Although there are a few potential risks, sufficient data exist to support the use of chromoendoscopy in the management of early gastric cancer. Therefore, chromoendoscopy is commonly used in tertiary referral centers around the world and even in general hospitals in Japan; however, it is otherwise not currently in widespread use in the rest of the world. Potential barriers to the widespread use of chromoendoscopy include perceptions of its inefficiency and exorbitant cost, lack of standardized training in techniques, and a deficiency of high-quality comparative studies. There is a need to build consensus on the techniques, interpretation of findings and terminology, in addition to proving its efficacy and reproducibility in high-quality, randomized, controlled trials before it can be incorporated into routine practice worldwide.

In summary, in order to establish the feasibility of hematoxylin chromoendoscopy, further investigation into its safety and relevance to significant clinical outcome are anticipated. When we use chromoendoscopy with hematoxylin in a clinical setting, informed consent should be obtained from patients and approval from institutional review boards may be required, as the potential hazards need to be balanced with possible benefits.

\section{References}

1. Mouzyka S and Fedoseeva A. Chromoendoscopy with hematoxylin in the classification of gastric lesions. Gastric Cancer 2008;11: $15-22$.

2. Bancroft JD, Stevens A. Theory and practice of histological techniques. 2nd ed. Edinburgh \& London: Churchill Livingstone; 1982.

3. SIRI MSDS Index. [Cited 2008 Feb 27]. Available from http:// www2.siri.org/msds/index.php.

4. Davies J, Burke D, Olliver JR, Hardie LJ, Wild CP, Routledge MN. Methylene blue but not indigo carmine causes DNA damage to colonocytes in vitro and in vivo at concentrations used in clinical chromoendoscopy. Gut 2007;56:155-6.

5. ASGE Technology Committee, Wong Kee Song LM, Adler DG, Chand B, Conway JD, Croffie JM, Disario JA, et al. Chromoendoscopy. Gastrointest Endosc 2007;66:639-49. 